\title{
AIRBORNE CONTACT DERMATITIS AND ASTHMA IN A NAIL ART OPERATOR
}

\author{
MARIO VACCARO, FABRIZIO GUARNERI, OLGA BARBUZZA, and SERAFINELLA PATRIZIA CANNAVÒ
}

University of Messina, Messina, Italy

Department of Clinical and Experimental Medicine - Dermatology

\begin{abstract}
Nail art (creation and decoration of artificial nails) is a growing fashion trend. Proportionally to its popularity, the number of allergic reactions to the materials used has recently increased. We report the case of a nail art operator who developed occupational allergy to acrylates, manifested with the unusual simultaneous presence of asthma and dermatitis. Cutaneous lesions only affected areas not covered by individual protection devices or clothes, even if such areas were not in direct contact with acrylates, suggesting airborne allergic contact dermatitis. While respiratory problems were solved with the correct use of a mask at the workplace, facial dermatitis proved impossible to avoid or control and, for this reason, the patient had to change her work.
\end{abstract}

Key words:

Occupational asthma, Acrylates, Airborne allergic contact dermatitis, Nail art

\section{INTRODUCTION}

Nail art is a recent and rapidly growing fashion trend, consisting in the creation of artificial nails, usually with acrylic resins, and their decoration with various techniques. Proportionally to its popularity, reports of allergy, not only among clients, but also among beauticians operating in this field, are becoming more and more frequent.

\section{CASE REPORT}

A 38-year-old woman, who was working as a nail art operator since she was 36 , came to observation because of facial dermatitis and multiple episodes of asthma that occurred in the previous two months. She reported that all respiratory symptoms and worsening of dermatitis happened at her workplace, a rather small and not well ventilated room where she created nail decorations using acrylic resins.
Clinical manifestations occurred despite the use of protection devices (a mask, nitrile gloves), avoidance of direct or mediated skin contact with working materials and handwashing before and after the use of gloves. Remission of asthma and improvement of dermatitis were observed on the days when the subject did not work. In addition, the patient reported that self-measurement of PEF (Peak of Expiratory Flow) with a portable device, as suggested by her pneumologist, showed lower values at the workplace (65-70\% of the predicted values) than at home (> 75\% of the predicted values). Clinical history was negative for significant diseases, including allergy, and the use of medications, even occasional; routine laboratory test results were within normal ranges.

Examination showed symmetrical erythematous-edematous lesions in the periorbital and zygomatic area, and in two thin strips on each cheek (Photo 1, published with the

Received: November 11, 2013. Accepted: December 20, 2013.

Corresponding author: F. Guarneri, University of Messina, Department of Clinical and Experimental Medicine - Dermatology, Via Consolare Valeria - Gazzi, 98125 Messina, Italy (e-mail: f.guarneri@tiscali.it). 


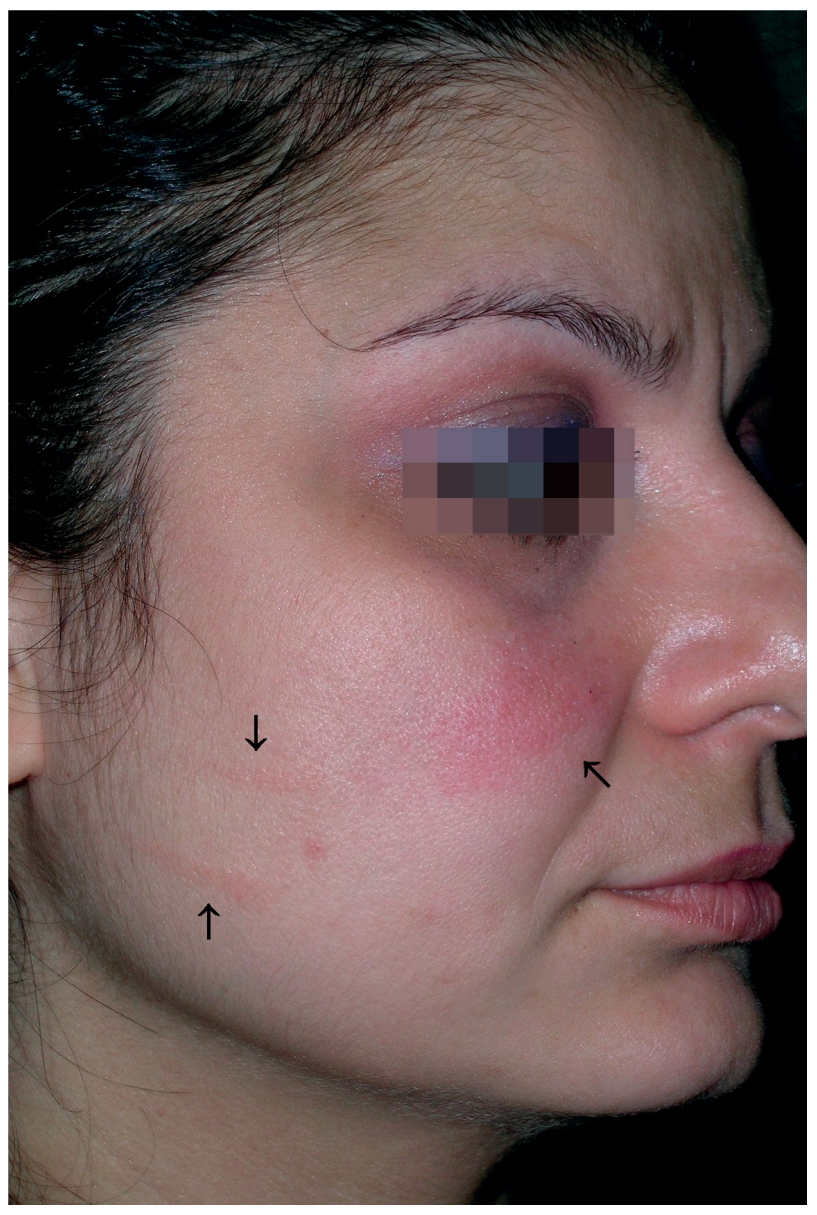

Photo 1. Periorbital, zygomatic and facial erythematousedematous lesions, pointed out by arrows

patient's informed consent). Spirometry (with a QuarkSPIRO spirometer, COSMED, Roma, Italy) showed mild airflow obstruction: forced expiratory volume in 1 second $\left(\mathrm{FEV}_{1}\right)$, forced vital capacity $(\mathrm{FVC})$, and $\mathrm{FEV}_{1} / \mathrm{FVC}$ ratio equaled $73 \%, 89 \%$, and $77 \%$ of the predicted values, respectively. The results were worse when spirometry was performed at the workplace: $\mathrm{FEV}_{1}, \mathrm{FVC}$ and $\mathrm{FEV}_{1} / \mathrm{FVC}$ were $64 \%, 78 \%$ and $69 \%$, respectively.

The bronchial provocation test performed according to the guidelines of ATS/ERS (American Thoracic Society/ European Respiratory Society) [1] with a DeVilbiss 646 nebulizer (Sunrise Medical, Somerset, USA) driven by the KoKo Digidoser system (Pulmonary Data Service, Louisville, USA) revealed mild bronchial hyper-responsiveness: a $20 \% \mathrm{FEV}_{1}$ decrease from the baseline with a $2 \mathrm{mg} / \mathrm{ml}$ provocative concentration of methacholine. The reversibility test, performed according to the guidelines of ERS/ ATS [2], showed a $14 \%$ increase of $\mathrm{FEV}_{1} 15$ min after administration of a short acting beta agonist (salbutamol). Prick tests with commercial extracts of aeroallergens, food allergens and latex, performed according to the guidelines of SIAIC (Società Italiana di Allergologia ed Immunologia Clinica - Italian Society of Allergy and Clinical Immunology) [3] were negative. The patch test was conducted according to the recommendations of ICDRG (International Contact Dermatitis Research Group) [4] and SIDAPA (Società Italiana di Dermatologia Allergologica, Professionale e Ambientale - Italian Society of Allergological, Occupational and Environmental Dermatology), with the use of baseline (standard) rubber, cosmetics and acrylate series (methylacrylate 1\%, methyl methacrylate $5 \%$, hydroxyethyl methacrylate $5 \%$, hydroxypropyl methacrylate $2 \%$, tetraethyleneglycol dimethacrylate $2 \%$, triethyleneglycol dimethacrylate $2 \%$, urethane dimethacrylate $2 \%$, bis-GMA $2 \%$, tetrahydrofurfuryl methacrylate $2 \%$, hexanediol diacrylate $0.1 \%, \mathrm{~N}, \mathrm{~N}$-dimethylaminoethyl methacrylate $0.2 \%$ and ethyleneglycol dimethacrylate $2 \%$, all in petrolatum), using haptens from FIRMA (Florence, Italy) in Hayes' chambers (Hayes Service BV, Alphen, the Netherlands). The results at D2 and D4 were positive for all acrylates except bis-GMA (Table 1 and Photo 2).

Our patient then specified that the symptoms occurred when she was using a nail drill machine to remove the preexisting nail decorations. The workplace inspection revealed that the protective mask, worn incorrectly, allowed inhalation of unfiltered air, and that dermatitis was localized in the areas not covered by the mask. We also performed the second patch test with the material obtained using the drill machine on the pre-existing nail decorations, with positive results $(+++)$ at D2 and D4; the same test was negative in ten subjects not allergic to acrylates. 
Table 1. Positive reactions to the patch test with acrylates observed at D4

\begin{tabular}{lc}
\hline \multicolumn{1}{c}{ Patch test } & Reaction \\
\hline Methyl acrylate 1\% pet. & +++ \\
Methyl methacrylate 5\% pet. & +++ \\
Hydroxyethyl methacrylate 5\% pet. & + \\
Hydroxypropyl methacrylate 2\% pet. & ++ \\
Tetraethyleneglycol dimethacrylate 2\% pet. & ++ \\
Triethyleneglycol dimethacrylate 2\% pet. & ++ \\
Urethane dimethacrylate 2\% pet. & + \\
Tetrahydrofurfuryl methacrylate 2\% pet. & ++ \\
Hexanediol diacrylate $0.1 \%$ pet. & ++ \\
N,N-dimethylaminoethyl methacrylate $0.2 \%$ pet. & +++ \\
Ethyleneglycol dimethacrylate 2\% pet. & ++ \\
\hline
\end{tabular}

pet. - petrolatum.

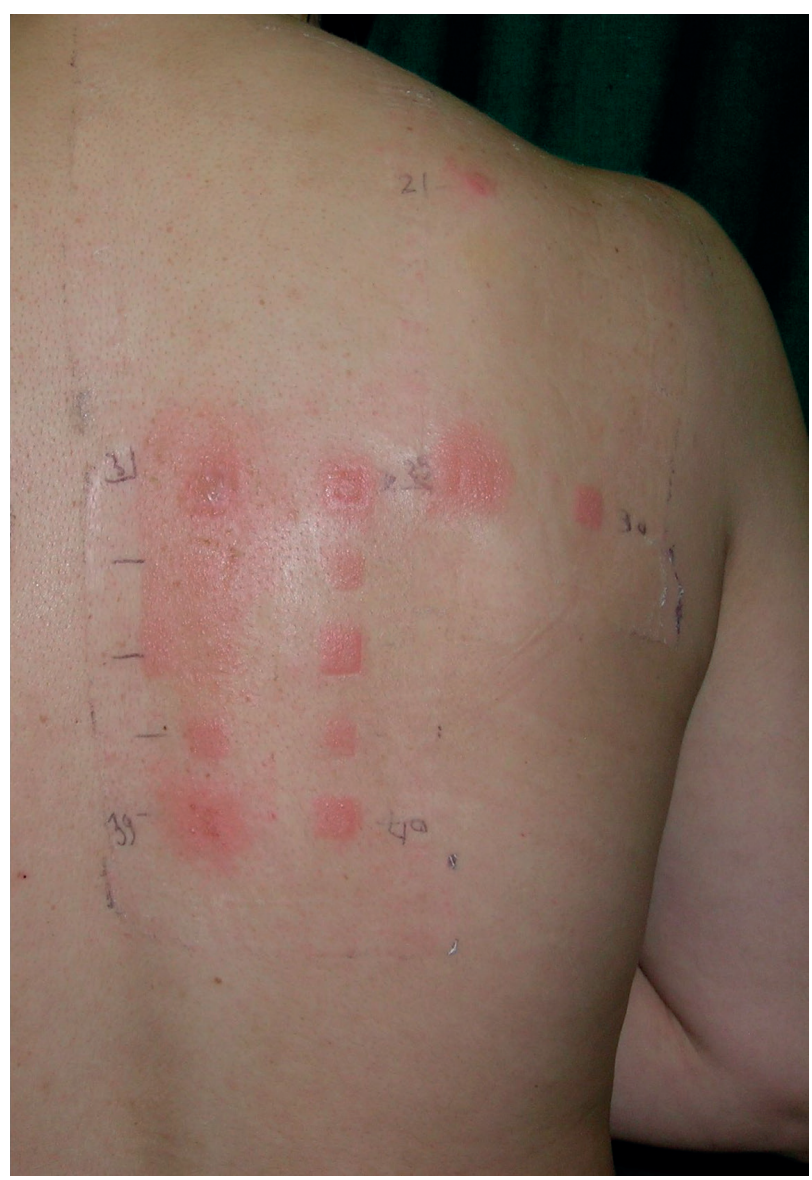

Photo 2. Positive results of the patch test to acrylates at D4
The manufacturer (Yiwu Qianshuo Nail Co., Ltd., Yiwu, Zhejiang, China) confirmed that some of the acrylates which our patient was allergic to were present in the products used (Lily Angel), but did not want to reveal the exact composition due to the fact that it was an industrial secret. We diagnosed airborne ACD (allergic contact dermatitis) and asthma caused by acrylates. The patient refused to be subjected to a bronchial challenge test with acrylates. Her asthma remarkably improved following the therapy (inhalation of fluticasone propionate $500 \mu \mathrm{g}$ twice a day for 15 days, then once a day for 15 days; salbutamol inhaled when necessary) and the correct use of a mask; conversely, antihistamines, topical/systemic corticosteroids, barrier creams and better working conditions did not significantly affect her dermatitis, which resolved when the patient quit her work. Six months after quitting work she reported that no further episodes of asthma or dermatitis had occurred; the skin examination revealed no lesions and spirometry was normal.

\section{DISCUSSION}

Allergy to acrylate-based artificial nails was first reported in 1957, but the frequency of this condition has significantly increased only recently. Cross-reactions among acrylates are common [5], and the wide and increasing dissemination of such materials in various fields, including medicine and esthetics, makes sensitization a considerable problem.

The clinical manifestation of this condition is varied: ACD (on nail folds, fingers, hands, forearms, face, neck) [6,7], onychodystrophy [8], pterygium inversum unguis [9], rhinitis [10], asthma [11]; possible airborne dermatitis was also reported [12]. The association of airborne ACD and asthma, both induced by acrylates, is not very frequently described in literature [13], and is probably still underestimated.

The proper use of adequate means of protection (nitrile or neoprene gloves and masks, as latex confers insufficient 
protection against acrylates) [14] is not always a definitive solution: our patient had to quit her activity, because no practical system existed to protect her face from particles of acrylic resin aerodispersed when removing the preexisting artificial nails.

In addition to providing the nail art operators and customers with information about the risks and methods of their prevention, research for new materials should be encouraged, to find out alternatives for allergic persons and avoid the incidence of similar cases in the future.

\section{REFERENCES}

1. Crapo RO, Casaburi R, Coates AL, Enright PL, Hankinson JL, Irvin CG, et al. Guidelines for methacholine and exercise challenge testing-1999. Official statement of the American Thoracic Society adopted by the ATS Board of Directors, July 1999. Am J Respir Crit Care Med. 2000;161:309-29.

2. Pellegrino R, Viegi G, Brusasco V, Crapo RO, Burgos F, Casaburi R, et al. Interpretative strategies for lung function tests. Eur Respir J. 2005;26:948-68, http://dx.doi.org/10.1183/ 09031936.05 .00035205 .

3. Tursi A, Bonini S, Businco L, Corsico R, Errigo E, Negrini AC, et al. [Memorandum on the diagnosis of allergic diseases]. Giorn It Allergol Immunol Clin. 1992;2:351-70. Italian.

4. Lachapelle JM, Maibach HI, editors. Patch testing and prick testing: A practical guide - official publication of the ICDRG. Berlin, Heidelberg: Springer Berlin Heidelberg; 2009.

5. Vaccaro M, Barbuzza O, Campo GM, Guarneri F. Late patchtest reaction to acrylates: A biochemical hypothesis. Dermatitis. 2009;20:E1-3.

6. Freeman S, Lee MS, Gudmundsen K. Adverse contact reactions to sculptured acrylic nails: 4 case reports and a literature review. Contact Dermatitis. 1995;33:381-5, http://dx.doi. org/10.1111/j.1600-0536.1995.tb02071.x.

7. Lazarov A. Sensitization to acrylates is a common adverse reaction to artificial fingernails. J Eur Acad Dermatol Venereol. 2007;21:169-74, http://dx.doi.org/10.1111/j.1468-3083. 2006.01883.x.

8. Cruz MJ, Baudrier T, Cunha AP, Ferreira O, Azevedo F. Severe onychodystrophy caused by allergic contact dermatitis to acrylates in artificial nails. Cutan Ocul Toxicol. 2011;30: 323-4, http://dx.doi.org/10.3109/15569527.2011.579928.

9. Paley K, English JC 3rd, Zirwas MJ. Pterygium inversum unguis secondary to acrylate allergy. J Am Acad Dermatol. 2008;58(2 Suppl):S53-4, http://dx.doi.org/10.1016/j.jaad. 2006.05.040.

10. Torres MC, Linares T, Hernandez MD. Acrylates induced rhinitis and contact dermatitis. Contact Dermatitis. 2005;53: 114, http://dx.doi.org/10.1111/j.0105-1873.2005.0650a.x.

11. Hannu T, Tuppurainen M, Kauppi P, Alanko K, HenriksEckerman ML, Sauni R. [Occupational asthma in a structure nail maker]. Duodecim. 2009;125:1209-13. Finnish.

12. Maio P, Carvalho R, Amaro C, Santos R, Cardoso J. Allergic contact dermatitis from sculptured acrylic nails:special presentation with a possible airborne pattern. Dermatol Online J. 2012;18:13.

13. Lindström M, Alanko K, Keskinen H, Kanerva L. Dentist's occupational asthma, rhinoconjunctivitis, and allergic contact dermatitis from methacrylates. Allergy. 2002;57:543-5, http://dx.doi.org/10.1034/j.1398-9995.2002.03199.x.

14. Andersson T, Bruze M, Gruvberger B, Björkner B. In vivo testing of the protection provided by non-latex gloves against a 2-hydroxyethyl methacrylate-containing acetone-based dentinbonding product. Acta Derm Venereol. 2000;80: 435-7, http://dx.doi.org/10.1080/000155500300012891.

This work is available in Open Access model and licensed under a Creative Commons Attribution-NonCommercial 3.0 Poland License - http://creativecommons.org/ licenses/by-nc/3.0/pl/deed.en. 